\title{
Assessment of high-dose inhalational corticosteroids vs systemic corticosteroids in acute exacerbations of COPD in diabetic patients
}

\author{
A.S. Magdy, Haytham S. Diab
}

Background Systemic corticosteroids (SCS) are effective in the management of acute exacerbation of chronic obstructive pulmonary disease (AECOPD). However, they are not without adverse effects, especially hyperglycemia. Inhaled corticosteroids (ICS) showed satisfactory outcomes with good safety. These benefits were not evaluated in patients with AECOPD with diabetes mellitus. The aim was to compare the efficacy and safety of high dose of ICS vs SCS in the treatment of AECOPD in diabetic patients.

Patients and methods A total of 126 patients with AECOPD were screened, and thirty of them were found to be eligible and were enrolled into two groups: group $1(n=15)$ received $1 \mathrm{mg}$ budesonide by jet nebulizer four times daily, and group 2 $(n=15)$ received $40 \mathrm{mg}$ prednisolone or equivalent systemically. Postbronchodilator forced expiratory volume in $1 \mathrm{~s}\left(\mathrm{FEV}_{1} \%\right)$ of predicted was measured at day 1 and day 7 , and random blood sugar (RBG) was measured twice daily in all patients.

Results There was a significant increase in the mean $\mathrm{FEV}_{1}$ at day 7 as compared with mean $\mathrm{FEV}_{1}$ at day 1 in groups 1 and 2, with the increase in mean $\mathrm{FEV}_{1}$ being 19.6 and $21 \%$ in groups 1 and 2, respectively. There was a significant difference, with higher mean RBG in group 2 when compared with group 1, at day 4 of treatment and continued onward. Interestingly, there was a significant elevation in mean RBG

\section{Introduction}

Acute exacerbation of chronic obstructive pulmonary disease (COPD) is characterized by progressive airflow limitation, and worldwide, it is presumed to become the third leading cause of death in 2030 [1].

Patients with COPD have a greater risk for diabetes mellitus (DM) type II [2]. Predisposing factors such as oxidative stress, systemic inflammation, insulin resistance, abnormal adipocyte metabolism, and weight increase, all participate in the ongoing pathophysiology. Moreover, diabetic patients with COPD have higher incidence for frequent COPD exacerbations compared with nondiabetics [3].

International guidelines highly advise systemic corticosteroids (SCS) in the treatment of AECOPD [4]. Moreover, International Guidelines for DM do not recommend corticosteroids in patients with DM owing to the hazards of hyperglycemia with incompetent diabetes control and increased risks for diabetes complications [5]. The presence of COPD together with DM is considered a big challenge for the treating clinicians [6]. among patients in group 2 (SCS) starting by day 3 of treatment and continued onward, with no significant rise in the first two days, although there was no evident effect of ICS on the mean RBG among patients in group 1 (ICS) during the follow-up days.

Conclusion Both ICS and SCS improve airflow in patients with AECOPD, taking into consideration the existence of diabetes mellitus. ICS may be an excellent substitute to SCS in the treatment of $A E C O P D$ in diabetic patients.

Egypt J Bronchol 2019 13:610-615

(c) 2020 Egyptian Journal of Bronchology

Egyptian Journal of Bronchology 2019 13:610-615

Keywords: acute exacerbation of chronic obstructive pulmonary disease, chronic obstructive pulmonary disease, diabetes mellitus, inhaled corticosteroids, postbronchodilator forced expiratory volume in $1 \mathrm{~s}$, systemic corticosteroids

Department of Pulmonary Medicine, Faculty of Medicine, Ain Shams University, Cairo, Egypt

Correspondence to Haytham S. Diab, MD, Department of Pulmonary Medicine and Respiratory Intensive Care Unit, Faculty of Medicine, Ain Shams University, Cairo, 11835, Egypt. Tel \& fax: 02247110 22; e-mail: haytham_samy@yahoo.com

Received: 23 August 2019 Accepted: 24 November 2019 Published: 21 January 2020

There are many variations between usage of SCS and inhaled corticosteroids (ICS). First, SCS have marked adverse effects on organs other than the lungs, but ICS have almost minimal systemic bioavailability. Second, anti-inflammatory effects of SCS begin after almost 6-7 $\mathrm{h}$ in the lungs, with peak effect after $24 \mathrm{~h}$; however, anti-inflammatory effects of ICS occur within the first hour and reach the peak within a few hours [7].

Inhalation devices ameliorate the local drugs delivery in the airways; significant proportion of ICS still reach the systemic circulation especially at high doses either through lungs or gastrointestinal tract. Almost $10-40 \%$ of inhaled drugs reach their target locations in the airways, and the rest is swallowed and reaches gastrointestinal tract [8]. However, only a minimal portion reaches systemic circulation, as most of the swallowed dose first undergoes metabolism in the liver.

This is an open access journal, and articles are distributed under the terms of the Creative Commons Attribution-NonCommercial-ShareAlike 4.0 License, which allows others to remix, tweak, and build upon the work non-commercially, as long as appropriate credit is given and the new creations are licensed under the identical terms. 
Furthermore, after exerting its beneficial action in the airways, ICS finally get absorbed systemically leading to more extrapulmonary effects [9].

Recent studies revealed that ICS therapy in patients with COPD was not associated with the high risk of new-onset diabetes or hyperglycemia [10]. Nevertheless, another study shows the relation of ICS with DM and insulin resistance in patients with COPD [11]. The aim of this study is to compare the efficacy and safety of high-dose ICS and SCS in the treatment of AECOPD in diabetic patients.

\section{Patients and methods \\ Study design}

A prospective randomized single-blind study was conducted at Ain Shams University Hospital and Erfan Hospital, Jeddah, Saudi Arabia, during January 2015 to January 2016. The patients who met the inclusion criteria were allocated randomly into one of two groups: group 1 included the patients who received $1 \mathrm{mg}$ inhalation budesonide by jet nebulizer every $6 \mathrm{~h}$ for 7 days, and group 2 included the patients who received oral or intravenous $40 \mathrm{mg}$ prednisolone or equivalent once daily for 7 days. All the patients from the two groups received the other lines of the standard medications, according to the clinical indications and the decisions of the treating physicians. These include the standard bronchodilator therapy, antimicrobials in the presence of infection, oxygen therapy, and treatment of comorbid conditions. The treatment of DM consists of a standard regimen of fixed daily dose of long-acting insulin and supplemented with short-acting insulin three times before meals according to the capillary blood sugar level. In cases of occurrence of emergency clinical insults, the studied patients received medications suitable for their conditions at the discretion of the treating physicians.

\section{Study population}

A total of 126 patients with COPD exacerbation were screened for the study over 6 months; they visited the outpatient clinic or the Emergency Department for deterioration of their respiratory condition and required hospitalization according to their attending physician and were considered candidates for the study. Of these 30 patients, 25 males and five females were found to be eligible and were randomized into either group 1 (15 patients) or group 2 (15 patients).

The inclusion criteria were as follows: confirmed previous diagnosis of COPD according to the
Global Initiative for Chronic Obstructive Lung Disease (GOLD) criteria [12], confirmed previous diagnosis of DM according to the American Diabetes Association guidelines [13], a clinical diagnosis of COPD exacerbation according to the GOLD criteria [12], post-bronchodilator forced expiratory volume in $1 \mathrm{~s}\left(\mathrm{FEV}_{1}\right)$ was less than $80 \%$ of predicted at presentation (to exclude mild cases of COPD exacerbation that can be improved by traditional lines of treatment other than corticosteroids either inhaled or systemic), and agreement from the patients to be enrolled in the study.

The exclusion criteria were as follows: history or a previous diagnosis of asthma or atopy, the presence of blood eosinophilia (eosinophil count in the peripheral blood $>500 / \mu 1$ ), the use of SCS within the last 30 days, history of AECOPD within the last 30 days, presence of specific reasons for AECOPD like pulmonary embolism, pneumonia, pneumothorax and heart failure, risk of respiratory failure requiring mechanical ventilation, ICU admission, patients younger than 18 years, and refusal to participate in the study.

\section{Methods}

All patients were subjected to the following at presentation: thorough history taking and clinical examination; posteroanterior chest radiography; complete blood count; oxygen saturation measurement by pulse oximetry and/or arterial blood gas analysis on room air; postbronchodilator spirometry for measurement of $\mathrm{FEV}_{1} \%$ of predicted at day 1 and at day 7 using spirometer device (ZAN 600 USB nSpire Health GmbH, Oberthulba, Germany); severity assessment of AECOPD according to the GOLD criteria; and random blood glucose level (RBG) assessment at least twice daily for 7 days. The standard medication for DM and AECOPD were administered as described before including usage of jet nebulizer device (Norditalia electromedicali s.r.1.; MEGANEB, Brescia, Italy).

Age, sex, severity of AECOPD, postbronchodilator $\mathrm{FEV}_{1}$, and RBG measurements were recorded. Any adverse effect of the drug, deterioration of the medical condition, patient's withdrawal for any reasons, and death were also recorded.

The study was approved by the Research and Ethical Committee in Chest Disease Department Ain Shams University and Dr Erfan and Bagedo General Hospital at November 2014. 


\section{Study end points}

The primary end point was to show and compare between the changes in postbronchodilator $\mathrm{FEV}_{1}$ at day 1 and at day 7 of treatment in both groups.

The secondary end point was to evaluate the random blood glucose level in both studied groups before, during, and after treatment.

\section{Statistical methods}

Data were revised for completeness and consistency. Double data entry on SPSS program version 20 (SPSS Inc., Chicago, Illinois, USA) was done. Quantitative data were summarized by mean and standard deviation, whereas qualitative data were summarized by frequencies and percentages. Student's $t$-test and Paired $t$-test were used in analysis of this paper. Moreover, generalized linear model with repeated measure analysis of variance was used in this study. The repeated measures design in this repeated measure analysis is a design in which each participant is measured each day for 7 days with respect to time. A ' $P$ value' of less than 0.05 was considered statistically significant and highly significant when ' $P$ value' was less than 0.01 .

\section{Results}

Thirty patients were enrolled in the study, who were divided randomly into two groups: group 1 was composed of 13 males and two females, who received ICS, with mean \pm SD age of $62 \pm 10.4$ years. Group 2 was composed of 12 males and three females, who received $\mathrm{SCS}$, with mean $\pm \mathrm{SD}$ age of $59.4 \pm 8.5$ years. There is higher mean age in group 1 compared with group 2 but there was no statistically significant difference between the two groups regarding sex and age.

There is no statistically significant difference between group 1 and group 2 regarding the mean of $\mathrm{FEV}_{1}$ / forced vital capacity (FVC) ratio on admission, $\mathrm{FEV}_{1}$ at day 1 , and $\mathrm{FEV}_{1}$ at day 7.

With taking into consideration that means of $\mathrm{FEV}_{1}$ at day 1 and $\mathrm{FEV}_{1}$ at day 7 among cases in group 1 being slightly lower than cases in group 2, as shown in Table 1, this proved to have comparable outcomes of ICS and SCS among patients with COPD with DM.

There is a highly statistically significant increase in the mean $\mathrm{FEV}_{1}$ at day 7 as compared with mean $\mathrm{FEV}_{1}$ at day 1 in group 1 (ICS), with the increase in mean $\mathrm{FEV}_{1}$
Table 1 Comparison between the two groups (group 1: ICS and group 2: SCS) regarding means of $\mathrm{FEV}_{1} / \mathrm{FVC}$ ratio on admission, $\mathrm{FEV}_{1}$ at day 1 , and $\mathrm{FEV}_{1}$ at day 7

\begin{tabular}{lcccc}
\hline & $\begin{array}{c}\text { Group 1: ICS } \\
(N=15) \\
(\text { mean } \pm S D)\end{array}$ & $\begin{array}{c}\text { Group 2: SCS } \\
(N=15) \\
(\text { mean } \pm S D)\end{array}$ & $t$ & $P$ \\
\hline FEV $_{1} /$ FVC ratio on & $60.2 \pm 7.6$ & $58.3 \pm 10.3$ & 0.5 & 0.5 \\
admission & $60.3 \pm 19.3$ & $64.7 \pm 14.3$ & 0.7 & 0.4 \\
FEV $_{1}$ at day 1 & $72.1 \pm 15.2$ & $78.3 \pm 10.4$ & 1.3 & 0.2 \\
FEV $_{1}$ at day 7 &
\end{tabular}

$\mathrm{FEV}_{1}$, forced expiratory volume in $1 \mathrm{~s}$; FVC, forced vital capacity; ICS, inhaled corticosteroids; SCS, systemic corticosteroids.

Table 2 Comparison between the two groups (group 1: ICS and group 2: SCS) regarding means of $\mathrm{FEV}_{1}$ at day 1 and $\mathrm{FEV}_{1}$ at day 7

\begin{tabular}{|c|c|c|c|c|c|}
\hline & $\begin{array}{c}\mathrm{FEV}_{1} \text { at } \\
\text { day } 1 \\
(N=15) \\
\text { (mean } \\
\pm \mathrm{SD} \text { ) }\end{array}$ & $\begin{array}{c}\mathrm{FEV}_{1} \text { at } \\
\text { day } 7 \\
(N=15) \\
\text { (mean } \\
\pm \mathrm{SD} \text { ) }\end{array}$ & $\begin{array}{l}\text { Increase } \\
\text { in mean } \\
\mathrm{FEV}_{1}(\%)\end{array}$ & $\begin{array}{c}\text { Paired } \\
t\end{array}$ & $P$ \\
\hline Group 1: ICS & $\begin{array}{c}60.3 \\
\pm 19.3\end{array}$ & $\begin{array}{c}72.1 \\
\pm 15.2\end{array}$ & 19.6 & 8.1 & $0.000^{\star^{*}}$ \\
\hline Group 2: SCS & $\begin{array}{c}64.7 \\
\pm 14.3\end{array}$ & $\begin{array}{c}78.3 \\
\pm 10.4\end{array}$ & 21 & 7.5 & $0.000^{* *}$ \\
\hline
\end{tabular}

$\mathrm{FEV}_{1}$, forced expiratory volume in $1 \mathrm{~s}$; ICS, inhaled corticosteroids; SCS, systemic corticosteroids. ${ }^{\star \star}$ Highly significant.

being 19.6\% among patients of group 1 (which was calculated as mean $\mathrm{FEV}_{1}$ at day 7 -mean $\mathrm{FEV}_{1}$ at day 1/ mean $\mathrm{FEV}_{1}$ at day 1).

Moreover, there is a highly significant statistical increase in the mean $\mathrm{FEV}_{1}$ at day 7 as compared with mean $\mathrm{FEV}_{1}$ at day 1 in group 2 (SCS), and the increase in mean $\mathrm{FEV}_{1}$ is $21 \%$ among group 2 . Interestingly, the increases in mean $\mathrm{FEV}_{1}$ between day 1 and day 7 in both groups were almost nearer to each other, as shown in Table 2.

There is no statistically significant difference between the two groups regarding mean random blood glucose in day 1 , day 2 , and day 3 of treatment, but at the start of day 4 and continued on day 5 , day 6 , and day 7 , there is a statistically significant difference between the two groups, with higher mean random blood glucose in group 2 when compared with group 1, as shown in Table 3.

Among patients treated with ICS (group 1), there is no statistically significant difference in mean random blood glucose in different days of the treatment by generalized linear model and repeated measure analysis of variance, as shown in Table 4. This means that the mean random blood glucose did not differ statistically during the follow-up days, with no evident effect of 
Table 3 Comparison between the two groups (group 1: ICS and group 2: SCS) regarding the mean random blood glucose along follow-up days of the study

\begin{tabular}{|c|c|c|c|c|c|}
\hline & Group 1: ICS $(N=15)($ mean $\pm S D)$ & Group 2: SCS $(N=15)($ mean $\pm S D)$ & Mean difference (mg \%) & $t$ & $P$ \\
\hline Mean RBG day 1 & $267.6 \pm 104.3$ & $268.5 \pm 95.3$ & 0.9 & 0.02 & 0.9 \\
\hline Mean RBG day 2 & $264.0 \pm 99.7$ & $300.1 \pm 100.5$ & 36.1 & 0.9 & 0.3 \\
\hline Mean RBG day 3 & $271.3 \pm 99.7$ & $342.5 \pm 114.7$ & 71.2 & 1.8 & 0.08 \\
\hline Mean RBG day 4 & $278.8 \pm 101.3$ & $367 \pm 114.2$ & 88.2 & 2.2 & $0.03^{*}$ \\
\hline Mean RBG day 5 & $279.5 \pm 102.4$ & $394.9 \pm 117.6$ & 115.4 & 2.8 & $0.008^{\star *}$ \\
\hline Mean RBG day 6 & $272.2 \pm 102.3$ & $416.3 \pm 130.1$ & 144.1 & 3.3 & $0.002^{* *}$ \\
\hline Mean RBG day 7 & $269.8 \pm 101.0$ & $432.7 \pm 137.3$ & 162.9 & 3.7 & $0.001^{* *}$ \\
\hline
\end{tabular}

The mean difference was calculated by subtracting the mean value of group 2 (systemic corticosteroids) from group 1 (inhaled corticosteroids). ICS, inhaled corticosteroids; RBG, random blood glucose; SCS, systemic corticosteroids. *Significant. **Highly significant.

Table 4 Repeated measure analysis of variance (GLM model) for the mean random blood glucose among patients of group 1 (ICS)

\begin{tabular}{lcccc}
\hline & Mean RBG & SE & Tests within participant effect $F$ & $P$ \\
\hline Day 1 & 267.6 & 26.9 & & \\
Day 2 & 264.0 & 25.7 & & \\
Day 3 & 271.7 & 25.7 & 1.3 & 0.2 \\
Day 4 & 278.8 & 26.1 & & \\
Day 5 & 279.5 & 26.4 & & \\
Day 6 & 272.2 & 26.4 & & \\
Day 7 & 269.8 & 26.0 & & \\
\hline
\end{tabular}

ICS, inhaled corticosteroids; GLM model, generalized linear model; RBG, random blood glucose.

ICS on the mean random blood glucose among patients in group 1.

Among patients treated with SCS (group 2), there is a highly statistically significant difference between mean RBG in day 1 as compared with mean RBG in other days of treatment (days 2, 3, 4, 5, 6, and 7) and also between mean RBG in day 2 as compared with mean RBG in other days of treatment (days 3, 4, 5, 6, and 7) using pairwise comparison Bonferroni test, as shown in Table 5.

Otherwise, there is no significant difference between mean RBG in day 3 when compared with mean RBG in other days of treatment (days 4, 5, 6, and 7), between mean RBG in day 4 when compared with mean RBG in following days of treatment, between mean RBG in day 5 when compared with mean RBG in following days of treatment, and finally, between mean RBG in day 6 when compared with mean RBG in day 7 among patients treated with SCS (group 2), as shown in Table 5.

This means that the elevation of mean RBG among patients of group 2 from day 3 onward had no significant difference statistically. In other words, the significant elevation in mean RBG in COPD diabetic patients treated with SCS (group 2) started by day 3, with no significant rise in the first 2 days.
Table 5 Repeated measure analysis of variance (GLM model) for the mean random blood glucose among patients of group 2 (SCS)

\begin{tabular}{lcccc}
\hline & Mean RBG & SE & $\begin{array}{c}\text { Tests within } \\
\text { participant effect } F\end{array}$ & $P$ \\
\hline Day 1 & 268.5 & 24.6 & & \\
Day 2 & 300.1 & 25.9 & & \\
Day 3 & 342.5 & 29.6 & 28.1 & $0.000^{\text {** }}$ \\
Day 4 & 367.5 & 29.5 & & \\
Day 5 & 394.1 & 30.3 & & \\
Day 6 & 416.3 & 33.6 & & \\
Day 7 & 432.7 & 35.4 & & \\
\hline
\end{tabular}

ICS, inhaled corticosteroids; GLM model, generalized linear model; RBG, random blood glucose. ${ }^{\star *}$ Highly significant.

\section{Discussion}

Chronic systemic inflammation is mostly one of the common key factors between COPD and DM. Recent studies have revealed that $\mathrm{DM}$ is more frequent in patients with COPD and liable to affect their prognosis [14].

The current study reveals the homogenous results of both high doses of ICS and SCS in treating patients with AECOPD and DM regarding improvement of airflow limitation with the privilege of ICS in avoiding hyperglycemia that commonly occurred in SCS.

The results of this study illustrate the nearby comparable results of $\mathrm{FEV}_{1} / \mathrm{FVC}$ ratio between both groups and also $\mathrm{FEV}_{1}$ at day 1 between both groups (being slightly lower in group 1) and finally $\mathrm{FEV}_{1}$ at day 7 between both groups (being slightly lower in group 1), with no statistically significant difference between both groups concerning the aforementioned parameters.

Moreover, our results revealed a highly statistically significant increase in the mean $\mathrm{FEV}_{1}$ at day 7 as compared with mean $\mathrm{FEV}_{1}$ at day 1 in both groups (1 and 2), with increase in mean $\mathrm{FEV}_{1}: 19.6$ and $21 \%$ in groups 1 and 2, respectively. Interestingly, the increase in mean $\mathrm{FEV}_{1}$ between day 1 and day 7 in both groups 
was almost near to each other, which prove the comparable outcomes of ICS to SCS among patients with COPD with DM.

This coincided with the results of Maltais et al. [15], who studied 199 COPD with acute exacerbation, nondiabetic patients, divided in three groups (SCS, ICS, and placebo groups) in a multicenter, doubleblind, randomized study, and stated that the improvement in $\mathrm{FEV}_{1}$ after 3 days from treatment tended to be comparable in ICS group and SCS group, being smaller in ICS group; this difference was not statistically significant.

Moreover, our findings were in line with the findings of Gunen et al. [16] who enrolled 121 patients with AECOPD randomly sorted into three groups (one group received bronchodilator treatment with nebulized salbutamol $2.5 \mathrm{mg}$ every $6 \mathrm{~h}$, the second group received the same bronchodilator treatment plus intravenous of $40 \mathrm{mg}$ prednisolone/day, and the third group received the same bronchodilator treatment plus nebulized budesonide $1500 \mathrm{mg}$ every $6 \mathrm{~h}$ ) for 10-day follow-up duration to compare among the three groups regarding $\mathrm{FEV}_{1}$ and $\mathrm{FVC}$ before and after treatment, and they stated that $\mathrm{FEV}_{1}$ was improved in groups 2 and 3 in the same degree without any significant difference between the two groups $(P=0.057)$.

Moreover, our results were in consistence with Ding et al. [17] who studied 410 patients with AECOPD, in a prospective randomized single-blind study, comparing between ICS and SCS regarding improvement of $\mathrm{FEV}_{1} / \mathrm{FVC}$ ratio and $\mathrm{FEV}_{1}$ after 7 days treatment, and they found marked improvement of $\mathrm{FEV}_{1}$ in both patients who either received ICS or SCS, after 7 days of treatment, and the results were not significantly different between the two studied groups.

Furthermore, our results agreed with the results of Morice et al. [18] who compared nebulized budesonide ( $2 \mathrm{mg}$ twice daily) with oral prednisolone (30 $\mathrm{mg}$ once daily) in a randomized parallel-group study of 19 adults with severe acute airway obstruction during the 5 days of the study, and they showed that baseline $\mathrm{FEV}_{1}$ increased from 1.8 to 2.11 in the group that received oral corticosteroids compared with 1.9-2.0 1 in the group that received nebulized corticosteroid, with no statistically significant difference in response to treatments in both groups.

Sun et al. [19] had recruited 30 patients with acute exacerbation of COPD, randomly divided into two groups: group with inhaled budesonide ( $3 \mathrm{mg}$ Bid for 10 days) and group with systemic methylprednisolone IVI $40 \mathrm{mg}$ day for three days and then methylprednisolone tablets $8 \mathrm{mg}$ twice per day for 7 days. They revealed that the levels of $\mathrm{FEV}_{1} / \mathrm{FVC}$ and $\mathrm{FEV}_{1}$ were higher in the two groups, compared with that before treatment $(P<0.05)$, especially in the seventh day. Besides, no differences were found between the two groups $(P>0.05)$. Their results were in accordance with our results.

Our results showed that there is a statistically significant difference between the studied groups regarding mean random blood glucose, with higher mean random blood glucose started at day 4 and continued on day 5, day 6, and day 7 of treatment in group 2 (SCS) when compared with group 1 (ICS), which matched with the results of Maltais et al. [15], as a significant proportion of patients developed hyperglycemia in the group of SCS compared with group of ICS starting from day 3 of treatment. Furthermore, our results were in accordance with Verma et al. [20], who found in a cross-sectional study on 49 nondiabetic patients with COPD to assess the glycemic status on long-term corticosteroid therapy not less than 6 months that $8.33 \%$ of the patients who received ICS developed DM compared with $25 \%$ of the patients who received SCS, although this study differs from our study in variation of the study interval.

Furthermore, our results were in agreement with Ding et al. [17] who found that fasting blood sugar in the patients who received ICS was elevated $4.5 \%$ after 7 days treatment compared with the patients who received SCS (elevated 17\%).

Moreover, the results of our study were matched with Sun et al. [19] and Gunen et al. [16] who found that the incidence of hyperglycemia with usage of high doses of ICS is significantly less than usage of SCS.

Our results revealed that among the patients who received ICS (group 1), the mean RBG did not differ statistically during the follow-up days, with no significant effect of ICS on the mean RBG regarding day-by-day comparison. On the contrary, patients who received SCS (group 2) experienced statistically significant rise in the mean RBG starting from day 3 of treatment and continued onward regarding dayby-day comparison, but in the first 2 days, there was little elevation but nonsignificant. The latter findings revealed the medical effectiveness of ICS usage being safer than SCS regarding the development of 
hyperglycemia in patients with COPD with DM, although SCS could be used if it is urgently demanded in the first 2 days as it seems to be virtually safe.

In contrast to our results, Samy et al. [21] in a cohort study found an evident effect of high dose of ICS (fluticasone $1000 \mu \mathrm{g}$ or more/day or its equivalent dose from other corticosteroids molecules) on the onset of $\mathrm{DM}$ or progression of diabetic patients from oral hypoglycemic to insulin in patients with COPD. They revealed the systemic complications of ICS, resulting in hyperglycemia and the subsequent need for oral hypoglycemic drugs or increase in treatment dose. Interestingly, they stated that the risks are more pronounced when using higher doses of ICS usually given in the management of COPD, but usual doses of ICS are correlated with lower risks of development of $\mathrm{DM}$ and diabetes progression.

Our study has several limitations. There was no standard corticosteroid regimen for the treatment of COPD exacerbation, and short duration of follow-up might not be enough to detect longer duration drawbacks of ICS. Future studies should be established to assess the long-term influence of inhaled budesonide on clinical outcomes, such as frequency of COPD exacerbations.

\section{Conclusion}

In conclusion, high-dose inhaled budesonide may be an effective substitute to SCS in the treatment of AECOPD. Furthermore, inhaled budesonide has less systemic complications than SCS, as indicated by serial blood glucose measurements.

\section{Financial support and sponsorship}

Nil.

\section{Conflicts of interest}

There are no conflicts of interest.

\section{References}

1 World Health Organization. Chronic obstructive pulmonary disease (COPD): burden of COPD. http://www.who.int/respiratory/copd/burden/ en/ (accessed March 13, 2014).
2 Rana JS, Mittleman MA, Sheikh J, Hu FB, Manson JE, Colditz GA, et al. Chronic obstructive pulmonary disease, asthma, and risk of type 2 diabetes in women. Diabetes Care 2004; 27:2478-2484.

3 Mirrakhimov AE. Chronic obstructive pulmonary disease and glucose metabolism: a bitter sweet symphony. Cardiovasc Diabetol 2012; 11:132.

4 Celli BR, MacNee W. ATS/ERS Task Force,Standards for the diagnosis and treatment of patients with COPD: a summary of the ATS/ERS position paper. Eur Respir J 2004; 23: 932-946.

5 The NHMRC and the Diabetes Australia Guideline Development Consortium. National evidence based guidelines for the management of type 2 diabetes mellitus; 2005. Available at: http://www.nhmrc.gov.au/ publications/synopses/ di7todi13syn.htm. [Accessed on Jan 2005].

6 Caughey GE, Roughead EE, Vitry AI, McDermott RA, Shakib S, Gilbert AL. Comorbidity in the elderly with diabetes: identification of areas of potential treatment conflicts. Diabetes Res Clin Prac 2010; 87:385-393.

7 Belda J, Margarit G, Martinez C, Bellido-Casado J, Casan P, Torrejón M, et al. Anti-inflammatory effects of high-dose inhaled fluticasone versus oral prednisone in asthma exacerbations. Eur Respir J 2007; 30:1143-1149.

8 Allen DB, Bielory L, Derendorf H, Dluhy R, Colice GL, Szefler SJ. Inhaled corticosteroids: past lessons and future issues. J Allergy Clin Immunol 2003; 112 (3 Suppl): S1-S40

9 Pedersen S, O'Byrne PM. A comparison of the efficacy and safety of inhaled corticosteroids in asthma. Allergy 1997; 52 (Suppl 39):1-34.

10 O'Byrne PM, Rennard S, Gerstein H, Radner F, Peterson S, Lindberg B, et al. Risk of new onset diabetes mellitus in patients with asthma or COPD taking inhaled corticosteroids. Respir Med 2012; 106:1487-1493.

11 Reynolds RM, Labad J, Sears AV, Williamson RM, Strachan MW, Deary IJ, et al. Edinburgh type 2 diabetes study investigators: glucocorticoid treatment and impaired mood, memory and metabolism in people with diabetes: the Edinburgh type 2 diabetes study. Eur J Endocrinol 2012 166:861-868.

12 Global Initiative for Obstructive Lung Disease - Updated 2014. Global strategy for the diagnosis, management, and prevention of chronic obstructive pulmonary disease. Available at: http://www.goldcopd.org. [Accessed on Feb 2014]

13 American Diabetes Association 2015 guidelines. Available at: http://www. ndei.org/ADA-diabetes-management-guidelines-diagnosis-A1C-testing aspx. [Accessed on Jan 2015].

14 Feary JR, Rodrigues LC, Smith CJ, Hubbard RB, Gibson JE. Prevalence of major comorbidities in subjects with COPD and incidence of myocardial infarction and stroke: a comprehensive analysis using data from primary care. Thorax 2010; 65:956-962.

15 Maltais F, Ostinelli J, Bourbeau J, Tonnel AB, Jacquemet N, Haddon J, et al. Comparison of nebulized budesonide and oral prednisolone with placebo in the treatment of acute exacerbations of chronic obstructive pulmonary disease: a randomized controlled trial. Am J Respir Crit Care Med 2002; 165:698-703.

16 Gunen H, Hacievliyagil SS, Yetkin O, Gulbas G, Mutlu LC, In E. The role of nebulised budesonide in the treatment of exacerbations of COPD. Eur Respir J 2007; 29:660-667.

17 Ding Z, Li X, Lu Y, Rong G, Yang R, Zhang R, et al. A randomized, controlled multicentric study of inhaled budesonide and intravenous methylprednisolone in the treatment on acute exacerbation of chronic obstructive pulmonary disease. Respir Med 2016; 121:39e47.

18 Morice AH, Morris D, Matthew PL. Comparison of nebulized budesonide with oral prednisolone in the treatment of exacerbations of obstructive pulmonary disease. Pharmacol Ther 1996; 60:675-678.

19 Sun X, He Z, Zhang J, Deng J, Bai J, Li M, et al. Compare the efficacy of inhaled budesonide and systemic methylprednisolone on systemic inflammation of AECOPD. Pulmon Pharmacol Ther 2015; 31:111e116.

20 Verma VK, Nim RK, Kumar M, Singh P, Singh G, Singh AK. Assessment of glycemic status of COPD patients on long term corticosteroid therapy. Int $J$ Res Med Sci 2017; 5:3997-4002.

21 Samy S, Abbas K, Pierre E. Inhaled corticosteroids and the risks of diabetes onset and progression. Am J Med 2010; 123:1001-1006. 